\title{
Dietary Factors Affect Food Reward and Motivation to Eat
}

\author{
Rahul Pandit $^{a}$ Julian G. Mercer ${ }^{b}$ Joost Overduin ${ }^{c}$ Susanne E. la Fleur ${ }^{d}$ \\ Roger A.H. Adan ${ }^{a}$ \\ a Rudolf Magnus Institute of Neuroscience, Department of Neuroscience and Pharmacology, \\ University Medical Center Utrecht, Utrecht, the Netherlands, ${ }^{b}$ Obesity and Metabolic Health, \\ University of Aberdeen, Rowett Institute of Nutrition and Health, Bucksburn, Aberdeen, UK \\ AB21, ${ }^{c}$ Health Department, NIZO Food Research BV, Ede, ${ }^{d}$ Department of Endocrinology and \\ Metabolism, Academic Medical Center, University of Amsterdam, Amsterdam, the Netherlands
}

\author{
Key Words \\ Diet-induced obesity $\cdot$ Leptin resistance $\cdot$ Reward circuitry $\cdot$ Food addiction • \\ Food ingredients
}

\begin{abstract}
The propensity to indulge in unhealthy eating and overconsumption of palatable food is a crucial determinant in the rising prevalence of obesity in today's society. The tendency to consume palatable foods in quantities that exceed energy requirements has been linked to an addiction-like process. Although the existence of 'food addiction' has not been conclusively proven, evidence points to alterations in the brain reward circuitry induced by overconsumption of palatable foods that are similar to those seen in drug addiction. The diet-induced obesity paradigm is a common procedure to replicate features of human obesity in rodents. Here we review data on the effect of various obesogenic diets (high-fat, Ensure ${ }^{\mathrm{TM}}$, cafeteria type, sucrose) on the extent of leptin resistance, hypothalamic-neuropeptidergic adaptations and changes in feeding behavior. We also discuss to what extent such diets and properties such as macronutrient composition, physical structure, sensory stimuli, and post-ingestive effects influence the brain-reward pathways. Understanding the interaction between individual components of diets, feeding patterns, and brain reward pathways could facilitate the design of diets that limit overconsumption and prevent weight gain. Copyright $\odot 2012 \mathrm{~S}$. Karger GmbH, Freiburg
\end{abstract}

\section{Introduction}

In the past decade, increasing enthusiasm and debate has been generated on the concept of 'food addiction'. Even though the validity of such a process has so far not conclusively been proved [1], several researchers indicate similarities between over-eating and addiction [2, 
3]. Functional brain imaging studies in obese and addicted individuals have shown similar activation patterns when subjects are exposed to food or drugs of abuse. For instance, involvement of the brain reward circuit, one of the principal neuronal pathways responding to natural (food, sex) or drug rewards, has been consistently associated with obesity and addictive states $[4,5]$. Elevated dopamine levels in the nucleus accumbens noted in animals lever-pressing for food or receiving electrical stimulation of the lateral hypothalamus or systemic injections of cocaine or amphetamine [6] indicate that effects of both drugs and food converge on the midbrain dopaminergic circuit.

The role of genes regulating food intake and degree of adiposity is well-known [7]. Prominent examples include the leptin [8] and melanocortin systems [9]. Gene mutations in these neuropeptidergic systems are accompanied by obesity [10]. Even though human subjects with single-gene mutations are well suited for studying the function of a certain gene with respect to energy metabolism and reward sensitivity [11,12], animals with monogenic forms of obesity are far from perfect tools to model the current obesity epidemic. Instead, the rising incidence of obesity can be studied as interplay between predisposing genetic factors and the consumption of obesogenic diets. A range of such diets are used in laboratories to induce obesity in rodents [13]. Despite the fact that these diets differ substantially in macronutrient composition, taste, form, and period of availability, a cardinal consequence is the development of obesity, hyperinsulinemia, and hyperleptinemia [14, 15].

High-calorie diets rich in sugars and fat are considered highly palatable and are readily consumed by the population [16]. But, what makes these food items more 'desirable' compared to other low-calorie foods? Several authors argue that such diets are more 'rewarding' and have an addictive potential $[2,17]$. Thus, by identifying whether certain types of diets are more 'addictive' than others and the specific features (or components) of such diets that make them more 'rewarding', development of novel foods curbing overconsumption and weight gain can be attempted. Importantly, overconsumption of food can be viewed in the light of two mechanisms: i) disturbed homeostatic regulation of food intake or satiety mechanisms and ii) increased motivation to consume food. The mechanisms relating to disturbed homeostatic regulation of food intake or satiety are independent and far reaching topics and are beyond the scope of the current review. Readers are referred to other relevant literature [18-20].

The current review is divided into three sections and aims to understand how various obesogenic diets alter motivation for food reward. The first section gives an overview of the various laboratory diets used to model obesity in rodents. The second part delineates and compares behavioral and molecular data on these palatable diets with drugs of abuse in an attempt to elucidate how palatable diets modify the brain reward circuitry. In the final section, we try to focus on the individual (macronutrient composition, structure, sensory, biochemical and post-ingestive) properties of these diets and analyze their rewarding nature.

\section{Diet and Leptin Resistance}

\section{Diet-Induced Obesity}

Extensive study of rodent models of obesity caused by either single gene loss-of-function mutation or targeted transgenic knockout has identified a number of genes, the products of which are essential for normal regulation of body composition and body weight. These key regulatory genes are located on the energy intake rather than the energy expenditure side of energy balance, and a number of these are associated with the leptin-melanocortin hypothalamic pathway, thereby emphasizing the importance of this circuit. However, it is generally recognized that most obesity cases in the human population is not secondary to 
mutations in single genes essential to energy balance, but rather reflects a genetic predisposition to which many genes contribute. In this polygenic obesity, the obese genotype is exposed by the obesogenic environment of modern-day society, where there is free access to a variety of energy-dense, palatable foods and sedentary lifestyles are the norm. As a consequence, mechanistic studies of obesity have increasingly focused on rodent models where obesity is induced by dietary manipulation (diet-induced obesity), as a convenient model for the human situation. A range of rodent species, strain, and diet combinations have been employed in both rats and mice to generate diet-induced obesity [21], with outcomes recorded at the level of signaling from the periphery, such as leptin, insulin and gut peptides, and activity of brain signals in the hypothalamus and forebrain. Here, we will compare the impact of high-fat diets, cafeteria diets, the nutritionally complete liquid diet, Ensure ${ }^{\mathrm{TM}}$, and sucrose solutions on caloric intake, obesity, and the development of leptin resistance.

\section{Leptin Resistance}

The adipose tissue hormone, leptin, is secreted into the bloodstream in proportion to body adiposity and is elevated in common human obesity. This is despite the known catabolic role of leptin in the regulation of energy balance, i.e. reduction in food intake, elevation of energy expenditure, and overall drive towards negative energy balance. The failure of elevated leptin levels to control or reverse obesity suggests the existence of a leptin-resistant state [22]. Rodent studies have demonstrated two distinct components to leptin resistance - a resistance to peripherally administered leptin suggesting a failure of the hormone to access CNS target sites, and/or resistance to CNS leptin resulting from impaired responses in CNS neurons expressing the leptin receptor. Leptin resistance also accompanies the obesity associated with aging. Interestingly, there are a number of circumstances in which leptin resistance appears to be developmentally programmed to meet prevailing physiological requirements, including pregnancy, lactation, and seasonal body weight change (e.g. in the Siberian hamster; [23]).

\section{The Relationship between Diet-Induced Obesity and Leptin Resistance}

There is evidence of both direct and indirect effects of diet, and more particularly high-fat diet, on leptin resistance. Thus, high-fat diets can induce leptin resistance either directly in the absence of obesity or indirectly as a consequence of obesity and resultant high leptin levels. The direct effect is presumed to be due to dietary components or their metabolites acting upon leptin-sensitive neurons. The evidence in support of this direct effect, which comes principally from assessment of early changes in sensitivity following dietary manipulation and/or the feeding of energy-restricted rations to prevent excess weight gain, has been reviewed by Morrison et al. [24]. In contrast to the putative direct effects, most leptin resistance is characterized under conditions of an existing hyperleptinemia that down-regulates leptin receptors and stimulates the negative regulators, suppressor of cytokine signaling 3 (SOCS3) and protein tyrosine phosphatase 1B (PTP1B). Thus, the picture emerging from high-fat diet-induced obesity is that of leptin resistance as a cause and consequence of obesity. There is evidence from outbred rat strains which exhibit within-population differences in susceptibility to diet-induced obesity that inherent differences in leptin sensitivity prior to dietary manipulation may be predictive of weight gain $[25,26]$, i.e. leptin resistance predisposes towards or promotes obesity, although the precise relationship and the underlying mechanisms remain to be resolved [for review see 22]. A particularly relevant observation is that all models of leptin resistance develop obesity on a high-fat diet, whereas only a few will show this effect on a stock diet [22]). This suggests a link between leptin resistance and overconsumption of palatable diets, most likely involving food reward. 


\section{High-Fat}

A very wide range of high-fat diets have been used to induce obesity, with considerable variability in fat content and source, macronutrient composition, energy density, and physical formulation $[21,27,28]$. Most commonly, diets with either $45 \%$ or $60 \%$ fat by energy are employed, but variation in experimental specifics such as species, strain, duration of dietary manipulation, age at manipulation etc. all influence the precise phenotypic outcome. Whereas it may not be possible to identify an ideal high-fat diet, more standardization in dietary and experimental design would be advantageous. For diets with fat contents of greater than $40 \%$ by energy, Buettner et al. [27] concluded that animal fats and $\omega-6 / \omega-9$ fatty acid-containing plant oils will induce obesity whereas fish oil $\omega$-3-fatty acids will not.

Obesity and elevated leptin levels on high-fat feeding are accompanied first by resistance to leptin administered by peripheral injection and then by central leptin resistance, as outlined above. For example, in C57BL/6J mice fed a high-fat diet (45\% fat; D12451, Research Diets, New Brunswick, NJ, USA), food intake responses indicated resistance to peripheral leptin within 16 days, although AKR mice subjected to the same dietary manipulation were still sensitive at this point [29]. By 56 days, both mouse strains were insensitive to peripheral leptin, but the AKR mice were still sensitive to intracerebroventricular (ICV) leptin. Using the same diet with C57BL/6J mice, a separate study showed no effect of high-fat diet on peripheral leptin-induced STAT3 signaling in the hypothalamus after 4 weeks, but leptin sensitivity was abolished after 15 weeks, although an attenuated response to ICV leptin remained [30]. In a similar study, also in C57BL/6J mice, but using a bespoke high-fat diet with $59 \%$ fat by energy [31], peripheral and central sensitivity to exogenous leptin was examined after 1,8 , or 19 weeks on diet. Temporal development of leptin resistance was described, with the three time points being characterized by full sensitivity to peripheral leptin, central but not peripheral leptin sensitivity and reduced central leptin sensitivity, respectively. In line with the conclusions of Buettner et al. [27], the fat component of D12451 is contributed by a mixture of approximately 7:1 lard:soybean oil, whereas the bespoke diet contains 3:1 safflower oil:tallow stearin, i.e. both diets contain a mixture of plant oils and animal fats. The composition and origin of fat in the diet may influence not only the progression towards obesity, but also leptin signaling. The direct effect of high-fat diet on leptin resistance may reflect the direct action of fatty acids, triglycerides, and lipid molecules at leptin-sensitive neurons, a possible component of hypothalamic nutrient sensing [32], or an effect on leptin transport across the blood-brain-barrier [33]. Importantly, several high-fat test diets also include a substantial amount of sucrose in its composition (for example, in D12451 17\% of total calories comes from sucrose). This further complicates the interpretation of the effect of such diets on developing obesity and leptin resistance.

\section{Cafeteria Diets}

The high-fat diets referred to above are generally assumed to induce obesity as a result of palatability-driven over-consumption, but in most instances are fed as a single diet where the ratio of macronutrients effectively obliges the animal to consume what may be an unbalanced diet. This may not be palatability-driven overconsumption, but rather 'passive' overconsumption resulting from the obligatory consumption of the imposed macronutrient profile. It is interesting to observe how the composition of the diet changes when a combination of different defined diets is offered and the animal is able to select a macronutrient profile that matches its 'requirements' [34]. The combination of variety and palatability in a so-called 'cafeteria diet' is almost certainly a better model for the human food environment.

Cafeteria diet is a general term used to describe an energy-dense diet composed of a variety of food items representative of the Western diet. These food items tend to be high in both fat and sugar and consequently are often energy-dense. Such a diet has the advantage 
of allowing novelty, choice, and variety, which are key characteristics of the modern human food environment, but the heterogeneous nature of the foodstuffs, and their means of presentation, can complicate the calculation of precisely how many calories are being ingested and what macronutrient profile is being selected [35]. Nevertheless, cafeteria diets typically drive hyperphagia and over periods of several weeks will induce obesity. Whereas direct assessment of leptin resistance through administration of exogenous leptin to cafeteria-obese rodents does not appear to have been performed, this obesity is accompanied by hyperleptinemia and hyperinsulinemia, and as with high-fat diets the downstream consequences of hyperleptinemia are indicative of leptin resistance. Following 10 weeks of cafeteria feeding, where 4 palatable human foods were changed every day on a weekly rotation, elevated body weight, body fat, and leptin levels were accompanied by a downregulation of leptin receptor gene expression in the hypothalamus of male but not female rats [36], an indicator of reduced signaling through the receptor, at least in males.

The availability of a wide choice of calorie-dense food is an important determinant for the overconsumption witnessed in humans. Apart from the cafeteria diet that incorporates the aspect of choice, the free-choice, high-fat, high-sucrose (fcHFHS) diet is another example where the connection between a high-energy choice diet and developing obesity can be studied. Animals given a choice between lard (high fat), 30\% sugar (high sugar) solution and standard chow showed prolonged hyperphagia, progressive increase in body weight as well as increased fat mass and circulating leptin levels. Interestingly, in animals exposed to only lard or only sugar solution besides regular chow, the initial hyperphagic response and accelerated weight gain, was followed by normophagia and weight gain comparable to control chow-fed animals $[37,38]$. Thus, the presence of palatable (sucrose) and energy-dense (lard) components in obesogenic diets may be crucial in the development of hyperphagia-induced obesity.

\section{Ensure $^{T M}$}

Ensure $^{\mathrm{TM}}$ (Abbott Laboratories, Abbott Park, IL, USA) is a complete liquid diet that comes in a number of flavors, all of which increase total daily energy intake by approximately $15 \%$ when fed ad libitum as a supplement to stock (low-fat, low-sugar) diet pellets [39]. The most substantial body of work describing its use has come from the Sprague-Dawley rat model of diet-induced obesity. Here, chocolate Ensure was deployed by Levin and co-workers [40] as a palatable supplement to stimulate obesity in rats with a low weight gain response to an obesogenic high-sugar, high-fat pellet diet. However, it is now clear that ad libitum Ensure supplementation stimulates sustained caloric overconsumption and increased weight and body fat gain irrespective of original body weight trajectory in Sprague-Dawley rats [15] and irrespective of the pellet diet background [41]. Ensure supplementation clearly provides an element of dietary choice but even within a single rat strain (Sprague-Dawley) there can be considerable variability in the proportion of calories taken from the liquid feed. Thus in 400 g+ rats, given a choice of Ensure and the Research Diets High Energy (HE) diet, 82\% of calories were taken as the liquid [42], whereas in juvenile $100 \mathrm{~g}+$ rats Ensure intakeaccounted for only $23 \%$ of calories with the same dietary combination, and only for $55 \%$ of calories when Ensure was fed as a supplement to a stock pellet [41]. Nevertheless, provision of the Ensure supplement ad libitum is generally accompanied by increases in caloric intake, weight gain, body adiposity, and plasma leptin [41, 42], with a doubling of plasma leptin concentration, for example, when deployed as a supplement to stock pellet [41] (Mercer et al., unpublished data). Although we have no evidence of an effect of Ensure on leptin receptor gene expression in any of the above studies, when Ensure was used as a supplement against a background of one of two pellet diets (HE or stock) or a combination of the two [41], a comparison between rats that did not have Ensure and those that did revealed that Ensure affects the association between adipose tissue and circulating leptin through an overall 
depressive effect on leptin concentrations. Whereas there is no firm evidence of induction of leptin resistance by Ensure, engagement with the reward system is indicated in studies in which scheduled ( $3 \mathrm{~h}$ daily) access to Ensure down-regulated striatal opioid gene expression [43], although these changes appeared not to be accompanied by changes in body weight or presumably blood leptin levels.

\section{Sucrose}

There is a multitude of publications on the effects of feeding sucrose and other sugars to laboratory rodents, and a range of outcomes have been reported. For example, with a 32\% sucrose solution fed as an ad libitum supplement to stock pellet from weaning to 70 days of age, caloric intake was increased by $23 \%$ [44]. However, there was no difference in body weight, although percentage body fat was increased. A very similar outcome - elevated caloric intake but no effect on growth - was recorded in another study of weanling rats allowed access to $32 \%$ sucrose [45]. However, the variability in outcome between different studies is well illustrated by the outcome of feeding adult rats (up to 210 days of age) with the same concentration of sucrose solution, where no increase in total caloric intake was evident [46]. A direct comparison of sucrose, glucose, or fructose supplied as a $32 \%$ solution in addition to standard diet to 250-300 g rats resulted in the consumption of more calories, weight gain and increased body fat [47]. Using sucrose concentrations more akin to those found in commercial soft drinks, we have determined that $12.5 \%$ or $25 \%$ solutions fed ad libitum to 250-300 g rats displace stock pellet in the diet and increase overall caloric intake by $20-25 \%$ but have no effect on body weight or leptin levels following a 4-week manipulation, although body fat tends to be elevated in the $12.5 \%$ group (Mercer et al., unpublished data). In addition, when rats were subjected to $30 \%$ sucrose in addition to stock pellets for 4 weeks, significant increases in caloric intake, fat mass, and leptin were observed [37, 38]; however, this did not result in changes in leptin sensitivity (la Fleur et al., unpublished data). In a recent study, 3 out of 4 mouse strains tested showed increased caloric intake (11-25\%), weight gain, and body adiposity when fed a $34 \%$ sucrose solution for 40 days [48]. By contrast, $10 \%$ sucrose, although eliciting a powerful drinking response, did not elevate caloric intake to the same extent, and did not increase body weight or body fat significantly in any of 4 mouse strains, although there were trends towards excess weight gain in the three sensitive strains. Interestingly, the 'sucrose-resistant' FVB strain consumed more of each sucrose solution than the other three strains that went on to develop a relative obesity.

Taken together these studies raise doubts about sucrose feeding as the sole dietary manipulation as a reproducible model of diet-induced obesity, since outcomes appear to be heavily influenced by experimental details. The relatively small changes in body adiposity that do occur make it unlikely that there will be any effect on leptin sensitivity, which probably explains why this has not been systematically examined. However, interestingly, chronic fructose consumption will induce leptin resistance, and does so in the absence of obesity. Rats fed a $60 \%$ fructose diet for 6 months developed leptin resistance but had normal body adiposity and leptin levels [49]. These leptin resistant animals had increased susceptibility to diet-induced obesity on a high-fat diet. Table 1 gives an overview of various diets leading to obesity and their influence on leptin signaling.

\section{Diet and the Brain Reward Circuitry}

The previous section gives us a glimpse on the effects of diverse obesogenic diets culminating in obesity and leptin resistance. The current section takes a step forward and evaluates the influence of these diets (and diet components) on the brain reward circuitry. 


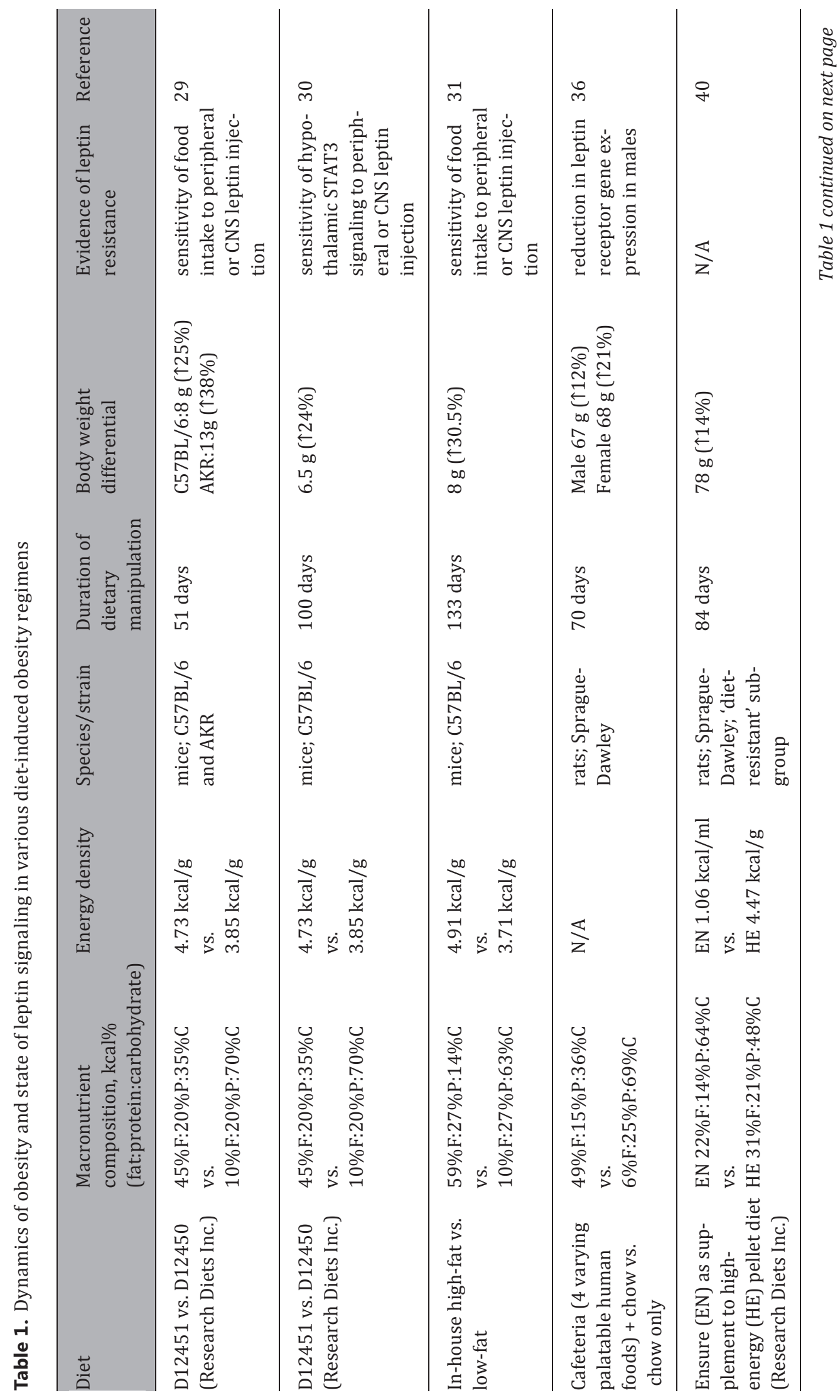



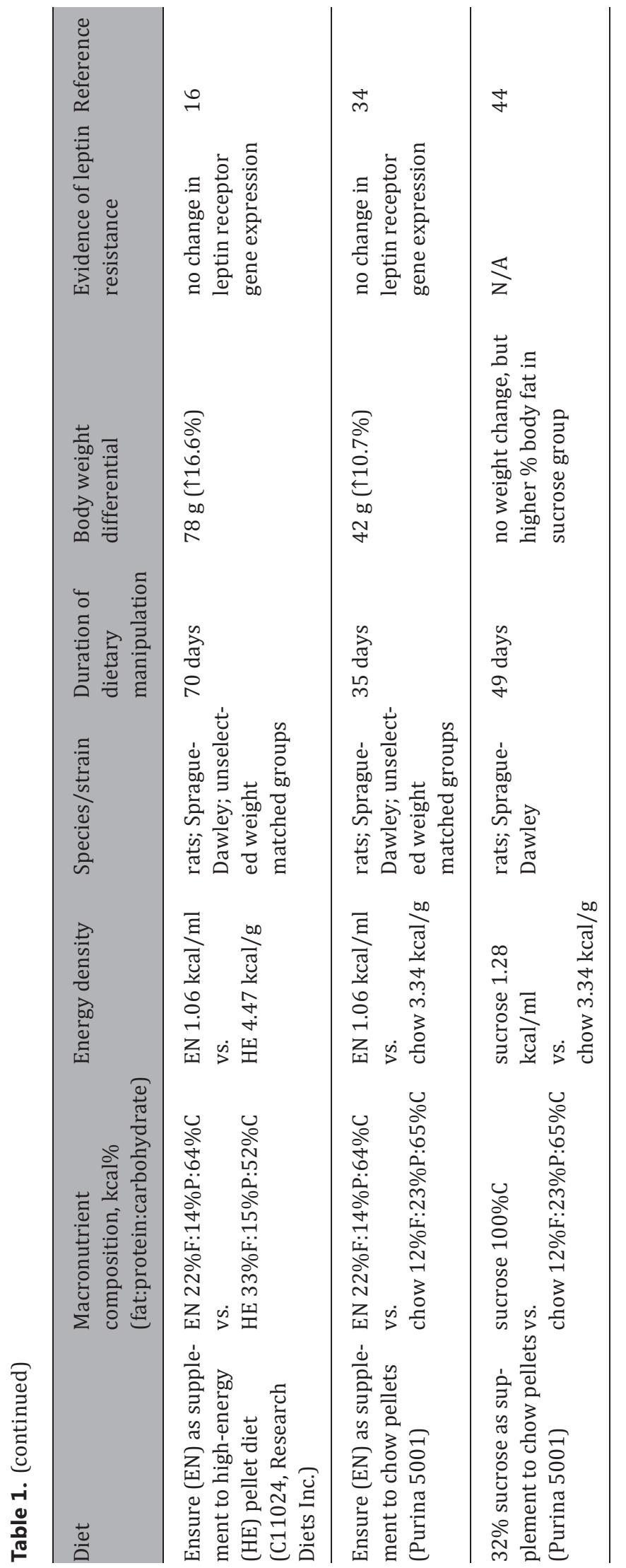

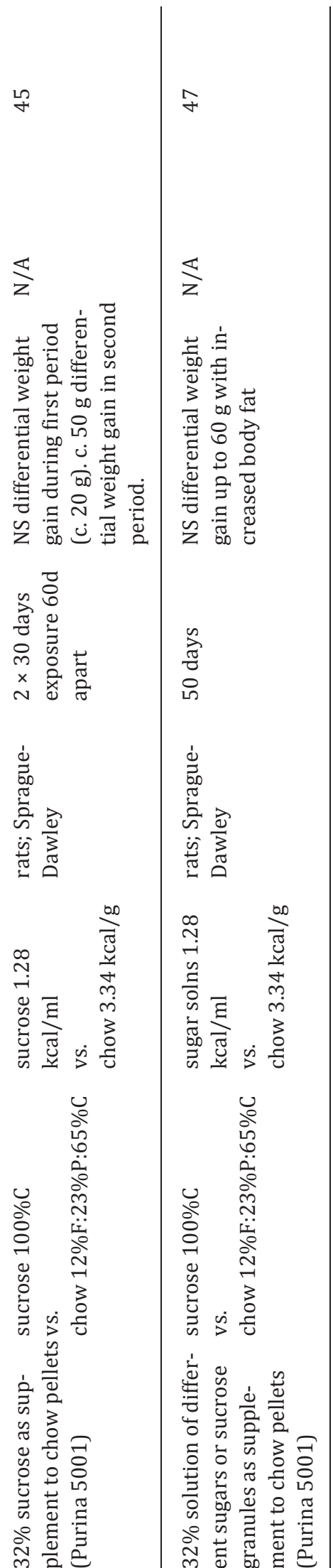

$\stackrel{\infty}{+}$

$\overleftrightarrow{z}$

ठ્ّ

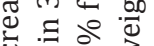

$\Xi$ 我

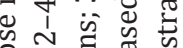

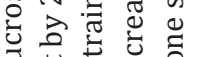

के से

음

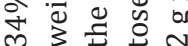

帘

우

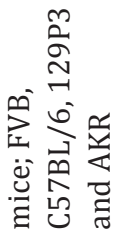

ت

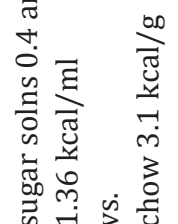

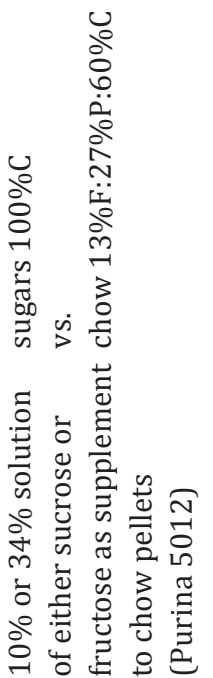


The brain reward circuit involves discrete nuclei: ventral tegmental area, nucleus accumbens, amygdalar complex, prefrontal cortex, and neurotransmitter systems, dopaminergic, GABAergic, opioid and serotonergic systems [50]. A majority of the studies conducted in rodents and humans focus on the mid-brain dopaminergic system. This system comprises a population of dopaminergic cells in the ventral tegmental area that project to the nucleus accumbens and the prefrontal cortex, among other brain areas [50]. The actions of dopamine in these target areas are mediated by two subsets of dopaminergic receptors: dopamine receptor type 1 and type 2 ( $D_{1}$ receptor and $D_{2}$ receptor).

\section{Sucrose}

Sucrose is perhaps the most widely studied dietary component that has been discussed with respect to its influence on the brain reward circuitry. A naturally occurring plant sugar, this disaccharide, comprising of the monosugars fructose and glucose, is a well known natural reinforcer and has been extensively used in behavioral research (operant learning, sucrose preference test). The relation between sucrose consumption and psychiatric states like substance dependence and mood disorders (e.g. anhedonia in depression) has been documented [51]. Studies with human subjects undergoing methadone treatment for addiction showed enhanced sucrose consumption in these patients compared to healthy women [52], and propensity to overindulge in sweet foods was noted in a cohort of drug addicts in Norway [53].

Extensive work in the field of 'sugar addiction' has been conducted by Hoebel and colleagues $[54,55]$. In their model of 'sugar addiction', schedule-fed rats that were repeatedly exposed to sugar solutions ( $10 \%$ sucrose or $25 \%$ glucose) in addition to standard laboratory chow engaged in binging $[54,55]$. In these animals, enhanced dopamine release in the nucleus accumbens shell [56], increased $\mathrm{D}_{1}$ receptor binding in the dorsal striatum and decreased $D_{2}$ receptor binding in the dorsal striatum and nucleus accumbens (core and shell) [54] were noted, a pattern of findings comparable to that observed in animals exposed to drugs of abuse [3]. Behavioral cross-sensitization experiments revealed that animals sensitized to amphetamine for 5 consecutive days, exhibit locomotor sensitization when exposed to $10 \%$ sucrose solution but not water [55]. Conversely, animals having intermittent access to $10 \%$ sucrose for 22 days showed heightened locomotor activity following low-dose amphetamine injection [56]. The paradigm used by Hoebel and colleagues [57, 58] involved food deprivation in the early dark phase (when animals are hungry and have a naturally high drive to eat), hence the effect of hunger (and low leptin levels) influencing sugar binging cannot be overlooked. Studies have consistently demonstrated a robust interaction between low leptin levels and heightened motivation. Food-restricted animals (i.e. low leptin levels) showed heightened sensitivity to drugs of abuse [59] and increased motivation to work for a palatable reward [60]. Contrarily, ICV administration of leptin decreased sucrose uptake in rats [60]. Thus leptin is implicated in modulating the reward system. For further details on the interaction between leptin and the brain reward circuitry, we refer the readers to Pandit et al., 2011 [18].

It is important to note that a combination of several factors (taste, caloric value, postingestive and sensory properties) act in concert when animals are exposed to sucrose solutions. But which of these individual factors actually play a role in making sucrose 'addictive' remains unknown. Cannon and Palmiter [61] concluded that sweet taste itself can be rewarding and the participation of dopaminergic system is not a prerequisite to experience the rewarding properties of sucrose. Dopamine-deficient mice given a choice between sweet solutions (sucrose and saccharin) and water preferred the former. However, the authors failed to dissociate the two facets of reward reinforcement: 'liking' and 'wanting' [62]. Preference for sweet solutions over water may simply indicate the enhanced 'liking' (an effect 
primarily mediated by the opioid system) in comparison to 'wanting' (involving the dopamine system). But, does sweet taste (rather than caloric value or nutrient type) influence the mesolimbic dopamine circuit? Animals sham-fed with varying concentrations $(0.3 \mathrm{~mol} / \mathrm{l}$, $0.1 \mathrm{~mol} / \mathrm{l}$, and $0.03 \mathrm{~mol} / \mathrm{l}$ ) of sucrose showed a dose-dependent increase in intake accompanied by augmented dopamine levels in the nucleus accumbens, underpinning the fact that orosensory properties of sucrose are important in determining the rewarding aspects of sucrose [63]. Contrarily, Ren and colleagues [64] demonstrated that mice devoid of functional sweet and bitter taste receptors, when given a choice between sucrose and an isocaloric amino acid solution, preferred the former. Intragastric infusions of sucrose in these mice showed enhancement of dopamine levels in the nucleus accumbens, stating that besides the orosensory and caloric properties of sucrose [65], nutrient type itself influences the mesolimbic dopaminergic circuit.

Many experimenters use saccharin, an artificial sweetener without any caloric value, to dissociate the orosensory properties of sucrose (also provided by saccharin) from its postingestive metabolic properties. Animals trained to self-administer ethanol or saccharin in a fixed ratio schedule of reinforcement of operant training showed increased lever pressing for saccharin and ethanol compared to water [66]. Additionally, non-food-deprived naïve animals exposed to saccharin showed increase in nucleus accumbens dopamine levels [67]. But, when subjected for longer periods to saccharin, this effect wore off $[66,68]$, indicating that elevated dopamine levels in naïve animals exposed to saccharin may be a novelty effect and not a consequence of the rewarding properties of the compound. Likewise, sucrose, but not saccharin, conditioned a place preference in rodents while the amounts ingested were equal in both cases, underpinning that place conditioning for sucrose is a function of postingestive metabolism of sucrose [69].

Fat

Saturated fats make up of a substantial portion of cafeteria/fast food diets. The level of fats in a diet correlates positively with palatability and negatively with satiety [70]. Lean and obese human subjects given a carbohydrate or a fat-rich diet showed increased hunger ratings and more caloric consumption in subsequent meals after a fat-rich breakfast [71]. Analogous findings with fat-rich diets being associated with a relatively low sense of fullness and increased sense of hunger have been documented [70, 72, 73]. This low satiating effect of fat-rich diets may be due to the slower digestion of fats that delays the post-absorbtive phase of satiety [71], thus augmenting the possibility of overindulgence in such diets.

The amount of data focusing on the effect of an exclusively high-fat diet on the brain reward circuitry is limited. Furthermore, the variability in the type of diet used in animal studies makes comparison of results across laboratories difficult $[13,74]$. The fat content in a high-fat diet [74], the type of fat (animal vs. plant) [37, 75], the flavor [76], the inclusion of other diet components besides fat (chow, sugar) [14,37], and the duration of access to the diet [77] all have an effect on the behavior and neurobiological alterations.

Using the conditioned place preference test, Figlewicz and colleagues [78] demonstrated that ad-libitum fed animals spent substantially more time in a high-fat paired compartment. Animals given restricted access to either vegetable shortening or a high-fat diet exhibited binge eating-like behavior $[75,79]$ reminiscent of the binge eating phenotype observed in rodents with limited access to sucrose $[54,55]$ or alcohol [80] solutions. Changes in the mesolimbic dopaminergic circuit include an initial increase in nucleus accumbens dopamine levels following exposure to a high-fat diet [81], followed by attenuated dopamine levels after more prolonged access [82]. Decrease in tyrosine hydroxylase (a rate-limiting enzyme in dopamine synthesis) messenger RNA was also observed in mice exposed to a high-fat diet for 6 weeks, which was not reversed when obese-prone animals were switched 
to and maintained on standard chow for 6 weeks [83]. Moreover, reduced dopamine levels were noted in obese-prone animals which were initially on a 5-day high-fat diet and later switched to a 2-week diet of standard laboratory chow, suggesting long lasting neurobiological modifications in response to high-fat diets [84]. Finally, reduced striatal $\mathrm{D}_{2}$ receptor levels were noted in response to prolonged exposure to a high-fat diet $[3,85]$. Collectively, these findings are in agreement with the neurobiological alterations that have been observed in rodent models of drug addition. Prolonged indulgence in drugs or high-fat diet leads to alterations in the mesolimbic dopaminergic circuitry, which may not be immediately reversible after discontinuation of the abused drug or high-fat food $[82,83,86]$.

\section{High-Fat, High-Sucrose Choice Diet}

Bearing in mind the availability of different high-calorie food choices in the market, the free-choice high-fat, high-sucrose diet is a relatively novel paradigm employed to study dietinduced obesity. Animals kept on this diet for 1 week demonstrated hyperphagia, hyperinsulinemia and leptinemia [14,37]. Exposure to this diet delayed the breakpoints in a progressive ratio scheme of reinforcement for a palatable reward [14]. Besides, the arcuate nucleus of these animals shows an increase in neuropeptide Y expression [37], a peptide well known for augmenting motivation in a progressive ratio paradigm [87]. Thus, augmented motivation in response to a high-fat, high-sucrose diet may be mediated by this neuropeptide. A recent paper evaluates the effect of this diet on the mesolimbic dopaminergic circuitry. Prolonged but restricted access to the high-fat, high-sucrose diet decreased $D_{1}$ and $D_{2}$ receptor levels in the nucleus accumbens, an effect unseen when animals are given unlimited access to this diet. Thus the observed alterations in $\mathrm{D}_{1}$ and $\mathrm{D}_{2}$ receptors are a direct consequence of the exposure to the diet rather than a result of the hyperphagia or obesity associated with this diet [88].

\section{Cafeteria Diet}

The cafeteria diet is another example where animals are given a choice of several highfat, high-sugar food items besides standard rodent chow to induce obesity [89-91]. Even though the compositions of such diets vary widely, a central feature includes the availability of high-caloric food components (rich in sugars and fat). Like most other palatable foods [73, 76], withdrawal from extended access to cafeteria diet leads to pronounced hypophagia [90, 92]. The basal (low) levels of dopamine in the nucleus accumbens after ad-libitum feeding on a cafeteria diet were augmented when animals were re-exposed to a cafeteria diet but not when exposed to standard chow [89]. These data echo the findings where animals given prolonged access to amphetamine, self-administer the drug to maintain a stable tonic level of dopamine in the nucleus accumbens [93]. Similar to drugs of abuse, decreased amounts of striatal $D_{2}$ receptors were seen in rats exposed to a cafeteria diet [90]. This reduction in $\mathrm{D}_{2}$ receptors was not only accompanied by deficits in reward sensitivity but also by compulsive food-seeking behavior in the light of adversity [90], a crucial criterion for the diagnosis of substance abuse [94]. Compulsive overconsumption of cafeteria food was also noted by Heyene and colleagues [95]. In their model, animals exposed to ad-libitum cafeteria dietfor 11 weeks showed inflexibility in increasing their chow intake coupled with depression of motor activity during limited access to cafeteria diet. In addition, cafeteria diet adulterated with a bitter taste was consumed by a substantial proportion of animals which were chronically exposed to this diet [95]. Thus, chronic exposure to 'addictive' substances (drugs or palatable foods) lowers the extracellular dopamine and $\mathrm{D}_{2}$ receptor levels in the nucleus accumbens, and animals respond to this neurochemical alteration by self-administration in excessive amounts of drugs or food to experience the same hedonic level (of subjective pleasure). 
Table 2. Evidence of interactions between various diet components and the brain reward circuitry (additional recommended references $[159,160])$

\begin{tabular}{|c|c|c|c|c|}
\hline Dietary components & 'Addiction-like' behavioral features & References & $\begin{array}{l}\text { Molecular changes in the meso-limbic } \\
\text { dopaminergic circuitry }\end{array}$ & References \\
\hline \multirow[t]{2}{*}{ Sucrose } & $\begin{array}{l}\text { limited access to sugars ( } 10 \% \text { su- } \\
\text { crose or } 25 \% \text { glucose) in addition to } \\
\text { standard chow, in late dark phase } \\
\text { produced a binging phenotype }\end{array}$ & 54,55 & $\begin{array}{l}\text { increased dopamine release in the } \\
\text { nucleus accumbens in animals binging } \\
\text { on sugar }\end{array}$ & 56 \\
\hline & $\begin{array}{l}\text { increased locomotor activity in } \\
\text { amphetamine-sensitized rats given } \\
10 \% \text { sucrose solution (behavioral } \\
\text { cross-sensitization) }\end{array}$ & 57,58 & $\begin{array}{l}\text { decreased D2 receptor binding in the } \\
\text { dorsal striatum in sugar binging ani- } \\
\text { mals }\end{array}$ & 156 \\
\hline \multirow[t]{2}{*}{ High-fat } & $\begin{array}{l}\text { place preference for fat-paired } \\
\text { chamber in ad libitum fed animals }\end{array}$ & 78 & $\begin{array}{l}\text { hypofunctioning?? of the mesolimbic } \\
\text { dopaminergic system following pro- } \\
\text { longed access to a high-fat diet }\end{array}$ & 82 \\
\hline & $\begin{array}{l}\text { restricted access to a high-fat diet } \\
\text { resulted in a binging phenotype }\end{array}$ & 75,79 & $\begin{array}{l}\text { reduced D2 receptor levels after ex- } \\
\text { tended access to a high-fat diet }\end{array}$ & 83,85 \\
\hline \multirow[t]{3}{*}{$\begin{array}{l}\text { High-fat high- } \\
\text { sucrose diet }\end{array}$} & hyperphagia & 38 & $\begin{array}{l}\text { limited and prolonged access to the } \\
\text { HFHS diet resulted in decreased D1 } \\
\text { and D2 receptor expression in the } \\
\text { nucleus accumbens }\end{array}$ & 88 \\
\hline & $\begin{array}{l}\text { increased motivation to respond to } \\
\text { a sucrose-reward in a progressive } \\
\text { ratio schedule of reinforcement }\end{array}$ & 14 & & \\
\hline & $\begin{array}{l}\text { increased motivation in a progres- } \\
\text { sive ratio paradigm in obese-prone } \\
\text { animals after withdrawal from the } \\
\text { diet }\end{array}$ & 157 & - . & \\
\hline \multirow[t]{2}{*}{ Cafeteria diet } & hyperphagia & 90,92 & $\begin{array}{l}\text { decreased levels of striatal D2 recep- } \\
\text { tors }\end{array}$ & 90 \\
\hline & $\begin{array}{l}\text { compulsive eating in the light of an } \\
\text { aversive stimulus (foot-shock, bitter } \\
\text { taste) }\end{array}$ & 90,95 & $\begin{array}{l}\text { animals with extended access to cafe- } \\
\text { teria diet showed augmentation of } \\
\text { dopamine levels in the nucleus accum- } \\
\text { bens in response to cafeteria diet but } \\
\text { not standard chow }\end{array}$ & 158 \\
\hline
\end{tabular}

\section{Opioids and Palatability}

Molecular cross-talk between the mesolimbic dopaminergic system and other neuropeptides at the level of the brain reward centers appears to regulate reward processing [96-98]. The endogenous opioid system, comprising of the opioid receptors ( $\delta-, \kappa^{-}, \mu$-opioid receptor) and their peptide ligands (endorphins, enkephalins, dynorphins) is distributed throughout the brain reward centers and has been implicated in drug addiction $[98,99]$. Opioids increase dopamine release in the nucleus accumbens by either increasing $\mu$ - and $\delta$-receptor activation in this area [100] or by diminishing GABA inhibition of the dopamin- 
ergic neurons in the ventral tegmental area [101]. Neurobiological correlates to the tolerance and dependence triggered by chronic opioid abuse includes the subdued sensitivity of the $\mu$-opioid receptor [98] and attenuated levels of endogenous opioids [102].

Analogous to their effects on the mesolimbic dopaminergic circuitry, obesogenic diets interact with the endogenous opioid circuitry. Down-regulation of enkephalin gene expression was noted after repeated ingestion of a highly palatable nutritionally complete liquid diet Ensure [43], reminiscent of the effects of chronic morphine exposure on striatal gene expression [102]. Since Ensure has a heterogeneous macronutrient composition (including carbohydrates, fats, proteins, and added flavors), the interdependence of the endogenous opioid system and individual macronutrient composition of diets remains undetermined.

Morphine-injected animals increased the consumption of fat [103], whereas treating animals with naloxone (a competitive $\mu$-opioid receptor antagonist that precipitates withdrawal symptoms in opioid addicts) attenuated fat intake [104]. Intra-accumbens injection of D-Ala2 N-Me-Phe4 Gly-ol5-enkephalin (DAMGO), a selective $\mu$-opioid receptor agonist, enhanced fat consumption in satiated rats [105]. This suggests that, similar to the effects of morphine [106], intake of high-fat food is mediated by the $\mu$-opioid receptor and involves the nucleus accumbens $[105,107]$, but the debate whether opioids specifically favor fat intake or promote the consumption of a preferred diet (fat vs. sugar) is ongoing [108].

Interactions between palatable foods other than fat and the endogenous opioid system have been reported $[109,110]$. For example, animals binging on sugar [55] exhibited signs of withdrawal when administered naloxone [110], and naloxone-treated animals decreased the amount of time spent in a sucrose-paired chamber in a conditioned place preference paradigm [111]. Likewise, withdrawal symptoms in morphine-dependent animals after naloxone treatment were attenuated when animals were given prior access to a $30 \%$ sucrose solution [112]. Despite the behavioral observations, underlying mechanisms dictating the interaction between the endogenous opioid system and palatable food intake remain undetermined. Evidence suggests that the morphine-induced preference for sucrose solutions [113] may be taste-dependent. ICV injection of DAMGO showed a dose-dependent enhancement in saccharin intake [114], and animals sham-fed with sucrose solutions exhibited a dose-dependent decrease in sucrose consumption when pre-treated with naloxone [115], excluding the possibility of post-ingestive effects of sucrose on the endogenous opioid system (readers are directed to an excellent review on this topic by Kelly et al. [116]). An overview of the interaction between various diets and the brain reward circuitry has been provided in table 2 .

Most of the current knowledge on the pathogenesis of obesity and the motivational aspects of palatable diet comes from rodent models. Hence, the current review is limited to experimental data on rodent species. Despite the relevance of the transition from rodent models to humans, studying the onset and development of obesity in humans is a challenging task bound by ethical and technical constraints. Research conducted on humans can be narrowed down to comparisons between obese subjects, obese subjects on decreased body weight and normal-weight controls [117], thus impeding the study of factors responsible for the development of obesity.

Nonetheless, the rapid development in the field of imaging techniques and psychological testing has enabled us to study and verify the similarities between neuroanatomical/ behavioral processes in humans as encountered in rodent models. Wang and colleagues [118] have shown an inverse relationship between $\mathrm{D}_{2}$ receptor availability and BMI in obese individuals, echoing the findings of several rodent studies. In addition, it was shown that, similar to processes observed in drug users, lower striatal $D_{2}$ receptor availability in obese humans correlated with decreased pre-frontal cortical metabolism, an area implicated in inhibitory control $[3,119]$. Finally, genome-wide association studies are yet another approach where 
human data are used to study a particular medical condition. It entails an analysis of differences in gene polymorphisms between diseased and healthy populations [120]. Although this approach enables us to identify candidate genes implicated in obesity, the use of animal models remain compelling for the verification of the role of these genes.

\section{Exploring the Role of Food Composition and Structure}

Initial hedonic ratings and long-term motivation to eat foods are weakly correlated [121]. Apparently, food reward is shaped not just by organoleptic stimuli such as aroma, taste and texture, but also by processes based on post-ingestive physiological signals that are registered as more or less rewarding by the CNS. The relationship between food properties and their sensory and physiological effects will be described next.

\section{Sensory Effects of Food}

Aroma, taste, and texture govern the decision to ingest or reject foods. Not surprisingly, the food industry puts major investment into product optimization to meet consumer preferences and motivate repeat purchase of foods [122]. This is well illustrated by the history of chocolate design. When introduced to Europe in the early 16th century, chocolate was only available as a relatively unprocessed, unpalatable, and gritty cocoa beverage with an oily surface layer. Centuries of technological innovation shaped today's highly rewarding chocolate bars. Nowadays, chocolate's attributes include a pleasant bite with just the right amount of snap (German: 'Knack'), fat crystals purposely designed to have an attractive gloss and melting point slightly below body temperature, cocoa particles ground to a size smaller than $20 \mu \mathrm{m}$ for a silky-smooth texture, and levels of sugar, fat and e.g. vanilla flavoring that are hedonically optimized to local taste [123]. Importantly, although the immediate appeal of chocolate is predominantly sensory, it is highly likely that repeated experience with its energy-delivering macronutrients (fat, sugar and - if present - milk protein) and neurochemical impact of its bioactive constituents (biogenic amines, methylxanthines and cannabinoid-like fatty acids) contribute to chocolate reward as well [124,125].

Food sensing can trigger acute physiological effects even before major nutrient metabolism sets in. Oral exposure to sucrose and fat stimulates dopamine release in the nucleus accumbens in rodents [126] and releases triglycerides from intestinally stored lipids and glucoregulatory hormones in humans [127]. Anticipatory physiological responses to scheduled meals can be learned, as shown for the hormone ghrelin [128] which activates CNS reward pathways and increases the motivation to eat $[129,130]$. Sensory effects of foods may influence energy intake via diverse learned and innate mechanisms [98, 131]. During food consumption, aromas are released retronasally in patterns that stimulate brain reward areas involved in motivation and increase satiation in humans $[132,133]$. Sugar and fat have synergistic effects on hedonic value and intake, but inhibitory effects on taste sensitivity [134].

\section{Energy Density, Stomach Fill, and Eating Rate}

The combination of high energy density (ED; number of calories per unit of food weight) and low market prices for snack foods has been blamed for today's overweight epidemic [135]. Relevantly for body weight management, ED is strongly increased by fat, while at the same time fat is poorly detected and relatively weakly satiating, facilitating energy overconsumption. To cope with this, a 'volumetrics' approach has been proposed as a tool to reduce caloric intake of diets that are still filling and satisfying [136]. This can be accomplished by increasing water or indigestible fiber content. One of the assumptions behind this approach is that noncaloric increases in food volume may stimulate oral and gastric signals that 
contribute to satiation, and possibly reward. An added benefit of ED reduction is that the lowered rate of energy intake may allow post-gastric (i.e., intestinal and post-absorptive) satiation signals sufficient time to limit meal size [137].

\section{Gastrointestinal and Post-Absorptive Signals}

De Araujo et al. [138] have shown that rodent strains with genetically ablated sweettaste transduction still develop preferences for sucrose and release brain dopamine after sugar consumption. This reveals a potent role of (nonsensory) gastrointestinal or postabsorptive signals in food reward.

The small intestine is a major source of post-meal humoral, neural, and metabolic signals with relevance for food reward [139]. Intestinal presence and absorption of digested food components is associated with local and systemic release of gastrointestinal satiation peptides, like CCK, GLP-1(7-36), PYY(3-36) and dozens of others, while blood levels of the orexigenic stomach hormone, ghrelin, are suppressed [140-142]. Of further relevance is the nutrient-related release of leptin and insulin, both of which can access the CNS and potentially influence the activity of pathways related to homeostatic and reward feeding [143]. Because the intensity and time course of the above mentioned gastrointestinal signals depend on food digestion, modifying food composition and structure could provide a practical approach to tune food reward signals in the CNS.

Food properties that modify post-meal physiological signals and - potentially - reward value include macronutrient composition $[139,140,144]$, choice of macronutrient subtypes (e.g. fructose vs. glucose;[145]), energy density, stomach acid-induced lumping and retention leading to prolonged bioavailability of proteins and carbohydrates [146, 147], and nutrient embedding or modification to control digestive rate $[148,149]$. Ingredients also interact post-ingestively. For example, in mixed meals, fat content may lower gastric emptying rate of carbohydrates and moderate the rise in blood glucose and plasma insulin [150], and glycemic index of diet appears to be relevant for weight control [151].

Following absorption from the intestinal tract, circulating fats, monosaccharides and amino acids may stimulate extra-intestinal hormone release (insulin, amylin, leptin) and/or enter the CNS to either activate or inhibit CNS pathways controlling homeostatic and reward feeding [152].

\section{Conclusion}

Regulation of food intake can be investigated as the function of two systems: homeostatic and hedonic regulation. The former is primarily achieved via hindbrain and hypothalamic control of food intake, while hedonic control of food intake occurs primarily by CNS reward circuitry. Despite this theoretical classification, the anatomical and functional distinction between these two systems is rather obscure. Firstly, connections exist between the hypothalamic nuclei maintaining homeostatic control of food intake and reward-related brain structures (lateral hypothalamus and nucleus accumbens), indicating a cross-talk between the two systems [153]. Secondly, receptors of various feeding peptides and peripherally produced satiety signals (e.g. leptin) are present in brain reward centers [154]. This interaction between the two systems is also seen in animals under food deprivation that increase their motivation to obtain a reward [60]. Moreover, humans have evolved in an environment where food availability was uncertain. Therefore, the concept of overeating as a survival mechanism to increase storage of energy as fat cannot entirely be dismissed. Based on this consideration, it seems likely that the homeostatic and hedonic regulation of feeding cannot simply be disentangled. 
Since past research in the field of 'food addiction' has been primarily directed at understanding the mechanisms by which the three macronutrients fat, protein, and carbohydrate influence brain reward circuitry, major advances should be expected from future research directed at i) improving our understanding of neurobiology of hedonic versus homeostatic consumption and ii) researching diets that would have a strong homeostatic component, but without generating changes in CNS as encountered after chronic drug use [3] or obesogenic diets $[14,37]$.

\section{Perspective}

Triggered by the increasing incidence of obesity due to overconsumption of high-caloric palatable foods, research on feeding behavior in the past decade has expanded its focus from strictly hypothalamic circuitries to include reward-related brain pathways.

The current review demonstrates that indeed certain high-caloric diets, mimicking the ones in today's western society influence brain reward centers and ,upon chronic exposure, generate molecular and behavioral changes similar to drugs of abuse. Importantly, in this research the role of specific components of these diets on the brain reward circuitry has received relatively little attention. Disintegrating complex diets into their individual components and studying the way the components modulate the brain reward circuitry would mean an essential next step towards improving our understanding on the interaction between food and brain reward pathways. Such research could inform the design of novel foods which are palatable yet fail to produce obesogenic consequences.

However, in pursuit of such an approach, assessing effects of single food components on reward and motivation to (over)eat seems a daunting task. Natural and processed foods alike are complex structures that may contain hundreds of components [155]. Therefore, at this moment a concept- rather than ingredient-driven experimental strategy may be most suitable. With this approach, validated sensory and physiological concepts guide food modifications of common model foods used in reward studies (i.e., sucrose solutions, nutritionally complete liquid meals) with the aim to modulate the reward value of food. Starting from these model foods, ingredients are added, modified, or replaced to alter food properties that are theoretically relevant to reward. These properties include aroma release, taste intensity, mouth feel, macronutrient composition, energy density, nutrient absorption rate, food digestibility, and concentration of bioactive substances.

Upon addition of these food variants to regular diet, measurements will be made to evaluate the energy intake, preference as well as anticipatory and motivational response to such novel diets. Subsequent studies will then evaluate how the food modifications tune peripheral physiological signals of appetite and satiation and affect the CNS. From an obesity management perspective, identifying foods with reduced energy density that are palatable yet do not evoke overconsumption could provide important rationales for food design while demonstrating the potential of combining insights from food technology and the neurobiology of feeding.

\section{Acknowledgement}

The work leading to this review has received funding from the European Community's Seventh Framework Programme (FP7/2007-2013 under grant agreement $\left.\mathrm{n}^{\circ} 245009\right)$. 
Pandit et al.: Dietary Factors Affect Food Reward and Motivation to Eat

\section{Disclosure Statement}

The authors report no conflict of interest.

\section{References}

1 Epstein DH, Shaham Y: Cheesecake-eating rats and the question of food addiction. Nat Neurosci 2010;13: 529-531.

2 Corsica JA, Pelchat ML: Food addiction: true or false? Curr Opin Gastroenterol 2010;26:165-169.

- 3 Volkow ND, Wang GJ, Fowler JS, Telang F: Overlapping neuronal circuits in addiction and obesity: evidence of systems pathology. Philos Trans R Soc Lond B Biol Sci 2008;363:3191-3200.

- 4 Beaver JD, Lawrence AD, van Ditzhuijzen J, Davis MH, Woods A, Calder AJ: Individual differences in reward drive predict neural responses to images of food. J Neurosci 2006;26:5160-5166.

5 Breiter HC, Gollub RL, Weisskoff RM, Kennedy DN, Makris N, Berke JD, Goodman JM, Kantor HL, Gastfriend DR, Riorden JP, Mathew RT, Rosen BR, Hyman SE: Acute effects of cocaine on human brain activity and emotion. Neuron 1997;19:591-611.

- 6 Hernandez L, Hoebel BG: Food reward and cocaine increase extracellular dopamine in the nucleus accumbens as measured by microdialysis. Life Sci 1988;42:1705-1712.

7 Flier JS, Maratos-Flier E: Lasker lauds leptin. Cell Metab 2010;12:317-320.

- 8 Tartaglia LA, Dembski M, Weng X, Deng N, Culpepper J, Devos R, Richards GJ, Campfield LA, Clark FT, Deeds J, Muir C, Sanker S, Moriarty A, Moore KJ, Smutko JS, Mays GG, Wool EA, Monroe CA, Tepper RI: Identification and expression cloning of a leptin receptor, OB-R. Cell 1995;83:1263-1271.

- 9 Adan RA, Gispen WH: Brain melanocortin receptors: from cloning to function. Peptides 1997;18:12791287.

10 Speakman J, Hambly C, Mitchell S, Krol E: Animal models of obesity. Obes Rev 2007;8(suppl 1):55-61.

11 Farooqi IS, Yeo GS, Keogh JM, Aminian S, Jebb S.A, Butler G, Cheetham T, 0’Rahilly S. Dominant and recessive inheritance of morbid obesity associated with melanocortin 4 receptor deficiency. J Clin Invest 2000;106: 271-279.

-12 Farooqi IS, Bullmore E, Keogh J, Gillard J, O’Rahilly S, Fletcher PC: Leptin regulates striatal regions and human eating behavior. Science 2007;317:1355.

13 van den Heuvel JK, van Rozen AJ, Adan RA, la Fleur SE: An overview on how components of the melanocortin system respond to different high energy diets. Eur J Pharmacol 2011;660:207-212

14 la Fleur SE, Vanderschuren LJ, Luijendijk MC, Kloeze BM, Tiesjema B, Adan RA: A reciprocal interaction between food-motivated behavior and diet-induced obesity. Int J Obes (Lond) 2007;31:1286-1294.

15 Mercer JG, Archer ZA: Diet-induced obesity in the Sprague-Dawley rat: dietary manipulations and their effect on hypothalamic neuropeptide energy balance systems. Biochem Soc Trans 2005;33:1068-1072.

16 Duffey KJ, Gordon-Larsen P, Jacobs DR Jr, Williams OD, Popkin BM: Differential associations of fast food and restaurant food consumption with 3-y change in body mass index: the Coronary Artery Risk Development in Young Adults Study. Am J Clin Nutr 2007;85:201-208.

17 Blumenthal DM, Gold MS: Neurobiology of food addiction. Curr Opin Clin Nutr Metab Care 2010;13:359365.

18 Pandit R, de Jong JW, Vanderschuren LJ, Adan RA: Neurobiology of overeating and obesity: the role of melanocortins and beyond. Eur J Pharmacol 2011;660:28-42.

19 Moran TH, Ladenheim EE: Adiposity signaling and meal size control. Physiol Behav 2011;103:21-24.

20 Woods SC, D’Alessio DA: Central control of body weight and appetite. J Clin Endocrinol Metab 2008;93:S3750 .

-21 Mercer JG, Archer ZA: Putting the diet back into diet-induced obesity: diet-induced hypothalamic gene expression. Eur J Pharmacol 2008;585:31-37.

-22 Scarpace PJ, Zhang Y: Leptin resistance: a predisposing factor for diet-induced obesity. Am J Physiol Regul Integr Comp Physiol 2009;296:R493-500.

23 Tups A, Ellis C, Moar KM, Logie TJ, Adam CL, Mercer JG, Klingenspor, M: Photoperiodic regulation of leptin sensitivity in the Siberian hamster, Phodopus sungorus, is reflected in arcuate nucleus SOCS-3 gene expression. Endocrinology 2004;145:1185-1193.

24 Morrison CD, Huypens P, Stewart LK, Gettys TW: Implications of crosstalk between leptin and insulin signalling during the development of diet-induced obesity. Biochim Biophys Acta 2009;1792:409-416.

-25 Levin BE, Dunn-Meynell AA, Ricci MR, Cummings DE: Abnormalities of leptin and ghrelin regulation in obesity-prone juvenile rats. Am J Physiol Endocrinol Metab 2003;285:E949-957.

26 Levin BE, Dunn-Meynell AA, Banks WA: Obesity-prone rats have normal blood-brain barrier transport but defective central leptin signalling before obesity onset. Am J Physiol Regul Integr Comp Physiol 2004; 286:R143-150.

27 Buettner R, Scholmerich J, Bollheimer LC: High-fat diets: modeling the metabolic disorders of human obesity in rodents. Obesity 2007;15:798-808. 
Hariri N, Thibault L: High-fat diet-induced obesity in animal models. Nutr Res Rev 2010;23:270-299.

-29 Van Heek M, Compton DS, France CF, Tedesco RP, Fawzi AB, Graziano MP, Sybertz EJ, Strader CD, Davis HR Jr: Diet-induced obese mice develop peripheral, but not central, resistance to leptin. J Clin Invest 1997;99: 385-390.

-30 El-Haschimi K, Pierroz DD, Hileman SM, Bjørbaek C, Flier JS: Two defects contribute to hypothalamic leptin resistance in mice with diet-induced obesity. J Clin Invest 2000;105:1827-1832.

-31 Lin S, Thomas TC, Storlien LH, Huang XF: Development of high fat diet-induced obesity and leptin resistance in C57Bl/6L mice. Int J Obes Relat Metab Disord 2000;24:639-646.

-32 Jordan SD, Könner AC, Brüning JC: Sensing the fuels: glucose and lipid signaling in the CNS controlling energy homeostasis. Cell Mol Life Sci 2010;67:3255-3273.

-33 Banks WA, Coon AB, Robinson SM, Moinuddin A, Shultz JM, Nakaoke R, Morley JE: Triglycerides induce leptin resistance at the blood-brain barrier. Diabetes 2004;53:1253-1260.

-34 Archer ZA, Corneloup J, Rayner DV, Barrett P, Moar KM, Mercer JG: Solid and liquid obesogenic diets induce obesity and counter-regulatory changes in hypothalamic gene expression in juvenile Sprague-Dawley rats. J Nutr 2007;137:1483-1490.

35 Rothwell NJ, Stock MJ: The cafeteria diet as a tool for studies of thermogenesis. J Nutr 1988;118:925-928.

-36 Plut C, Ribiere C, Giudicelli Y, Dausse JP: Hypothalamic leptin receptor and signaling molecule expressions in cafeteria diet-fed rats. J Pharmacol Exp Ther 2003;307:544-549.

- 37 la Fleur SE, van Rozen AJ, Luijendijk MC, Groeneweg F, Adan RA: A free-choice high-fat high-sugar diet induces changes in arcuate neuropeptide expression that support hyperphagia. Int J Obes (Lond) 2010;34: 537-546.

-38 la Fleur SE, Luijendijk MC, van Rozen AJ, Kalsbeek A, Adan RA: A free-choice high-fat high-sugar diet induces glucose intolerance and insulin unresponsiveness to a glucose load not explained by obesity. Int J Obes (Lond) 2011;35:595-604.

-39 Archer ZA, Brown YA, Rayner DV, Stubbs RJ, Mercer JG: Effect of flavour of liquid Ensure diet supplement on energy intake in male SD rats. Physiol Behav 2006;89:414-419.

40 Levin BE: Arcuate NPY neurones and energy homeostasis in diet-induced obese and resistant rats. Am J Physiol 1999;276:R382-387.

-41 Archer ZA, Corneloup J, Rayner DV, Barrett P, Moar KM, Mercer JG: Solid and liquid obesogenic diets induce obesity and counter-regulatory changes in hypothalamic gene expression in juvenile Sprague-Dawley rats. J Nutr 2007;137:1483-1490.

-42 Archer ZA, Rayner DV, Barrett P, Balik A, Duncan JS, Moar KM, Mercer JG: Hypothalamic energy balance gene responses in the Sprague-Dawley rat to supplementation of high-energy diet with liquid Ensure and subsequent transfer to chow. J Neuroendocrinol 2005;17:711-719.

-43 Kelley AE, Will MJ, Steininger TL, Zhang M, Haber SN: Restricted daily consumption of a highly palatable food (chocolate Ensure ${ }^{\circledR}$ ) alters striatal enkephalin gene expression. Eur J Neurosci 2003;18:2592-2598.

44 Kanarek RB, Marks-Kaufman, R: Developmental aspects of sucrose-induced obesity in rats. Physiol Behav 1979;23:881-885.

45 Sclafani A, Xenakis S: Sucrose and polysaccharide induced obesity in the rat. Physiol Behav 1984;32:169174.

-46 Hirsch E, Dubose C, Jacobs HL: Overeating, dietary selection patterns and sucrose intake in growing rats. Physiol Behav 1982;28:819-828.

47 Kanarek RB, Orthen-Gambill N: Differential effects of sucrose, fructose and glucose on carbohydrateinduced obesity in rats. J Nutr 1982;112:1546-1554.

-48 Glendinning JI, Breinager L, Kyrillou E, Lacuna K, Rocha R, Sclafani A: Differential effects of sucrose and fructose on dietary obesity in four mouse strains. Physiol Behav 2010;101:331-343.

-49 Shapiro A, Mu W, Roncal C, Cheng K-Y, Johnson RJ, Scarpace PJ: Fructose-induced leptin resistance exacerbates weight gain in response to subsequent high-fat diet. Am J Physiol Regul Integr Comp Physiol 2008; 295:R1370-1375.

50 Koob GF: Drugs of abuse: anatomy, pharmacology and function of reward pathways. Trends Pharmacol Sci 1992;13:177-184.

-51 Papp M, Willner P, Muscat R: An animal model of anhedonia: attenuation of sucrose consumption and place preference conditioning by chronic unpredictable mild stress. Psychopharmacology (Berl) 1991;104:255259.

52 Zador D, Lyons Wall PM, Webster I: High sugar intake in a group of women on methadone maintenance in south western Sydney, Australia. Addiction 1996;91:1053-1061.

-53 Saeland M, Haugen M, Eriksen FL, Wandel M, Smehaugen A, Bohmer T, Oshaug A: High sugar consumption and poor nutrient intake among drug addicts in Oslo, Norway. Br J Nutr 2011;105:618-624.

54 Colantuoni C, Schwenker J, McCarthy J, Rada P, Ladenheim B, Cadet JL, Schwartz GJ, Moran TH, Hoebel BG: Excessive sugar intake alters binding to dopamine and mu-opioid receptors in the brain. Neuroreport 2001;12:3549-3552.

55 Avena NM: The study of food addiction using animal models of binge eating. Appetite 2010;55:734-737.

56 Rada P, Avena NM, Hoebel BG: Daily bingeing on sugar repeatedly releases dopamine in the accumbens shell. Neuroscience 2005;134:737-744. 
Pandit et al.: Dietary Factors Affect Food Reward and Motivation to Eat

57

$>58$

$>59$

60

61

62

-63

Ren X, Ferreira JG, Zhou L, Shammah-Lagnado SJ, Yeckel CW,
of taste receptor signaling. J Neurosci 2010;30:8012-8023

65 de Araujo IE, Oliveira-Maia AJ, Sotnikova TD, Gainetdinov RR, Caron MG, Nicolelis MA, Simon SA: Food reward in the absence of taste receptor signaling. Neuron 2008;57:930-941.

-66 Melendez RI, Rodd-Henricks ZA, Engleman EA, Li TK, McBride WJ, Murphy JM: Microdialysis of dopamine in the nucleus accumbens of alcohol-preferring (P) rats during anticipation and operant self-administration of ethanol. Alcohol Clin Exp Res 2002;26:318-325.

67 Mark GP, Blander DS, Hoebel BG: A conditioned stimulus decreases extracellular dopamine in the nucleus accumbens after the development of a learned taste aversion. Brain Res 1991;551:308-310.

-68 Weiss F, Lorang MT, Bloom FE, Koob GF: Oral alcohol self-administration stimulates dopamine release in the rat nucleus accumbens: genetic and motivational determinants. J Pharmacol Exp Ther 1993;267:250258.

69 White NM, Carr GD: The conditioned place preference is affected by two independent reinforcement processes. Pharmacol Biochem Behav 1985;23:37-42.

70 Benton D: Can artificial sweeteners help control body weight and prevent obesity? Nutr Res Rev 2005;18: 63-76.

71 Blundell JE, Burley VJ, Cotton JR, Lawton CL: Dietary fat and the control of energy intake: evaluating the effects of fat on meal size and postmeal satiety. Am J Clin Nutr 1993;57(5 suppl):772S-777S; discussion 777S-778S.

72 Holt SH, Delargy HJ, Lawton CL, Blundell JE: The effects of high-carbohydrate vs high-fat breakfasts on feelings of fullness and alertness, and subsequent food intake. Int J Food Sci Nutr 1999;50:13-28.

73 Rolls BJ, Rowe EA, Turner RC: Persistent obesity in rats following a period of consumption of a mixed, high energy diet. J Physiol 1980;298:415-427.

74 Buettner R, Scholmerich J, Bollheimer LC: High-fat diets: modeling the metabolic disorders of human obesity in rodents. Obesity (Silver Spring) 2007;15:798-808.

-75 Corwin RL, Wojnicki FH, Fisher JO, Dimitriou SG, Rice HB, Young MA: Limited access to a dietary fat option affects ingestive behavior but not body composition in male rats. Physiol Behav 1998;65:545-553.

-76 Cottone P, Sabino V, Steardo L, Zorrilla EP: Intermittent access to preferred food reduces the reinforcing efficacy of chow in rats. Am J Physiol Regul Integr Comp Physiol 2008;295:R1066-1076.

77 Wojnicki FH, Babbs RK, Corwin RL: Reinforcing efficacy of fat, as assessed by progressive ratio responding, depends upon availability not amount consumed. Physiol Behav 2010;100:316-321.

-78 Figlewicz DP, Bennett J, Evans SB, Kaiyala K, Sipols AJ, Benoit SC: Intraventricular insulin and leptin reverse place preference conditioned with high-fat diet in rats. Behav Neurosci 2004;118:479-487.

79 Davis JF, Melhorn SJ, Shurdak JD, Heiman JU, Tschop MH, Clegg DJ, Benoit SC: Comparison of hydrogenated vegetable shortening and nutritionally complete high-fat diet on limited access-binge behavior in rats. Physiol Behav 2007;92:924-930.

-80 Lesscher HM, van Kerkhof LW, Vanderschuren LJ: Inflexible and indifferent alcohol drinking in male mice. Alcohol Clin Exp Res 2010;34:1219-1225.

81 Martel P, Fantino M: Mesolimbic dopaminergic system activity as a function of food reward: a microdialysis study. Pharmacol Biochem Behav 1996;53:221-226.

-82 Davis JF, Tracy AL, Schurdak JD, Tschop MH, Lipton JW, Clegg DJ, Benoit SC: Exposure to elevated levels of dietary fat attenuates psychostimulant reward and mesolimbic dopamine turnover in the rat. Behav Neurosci 2008;122:1257-1263.

-83 Li Y, South T, Han M, Chen J, Wang R, Huang XF: High-fat diet decreases tyrosine hydroxylase mRNA expression irrespective of obesity susceptibility in mice. Brain Res 2009;1268:181-189.

84 Rada P, Bocarsly ME, Barson JR, Hoebel BG, Leibowitz SF: Reduced accumbens dopamine in SpragueDawley rats prone to overeating a fat-rich diet. Physiol Behav 2010;101:394-400.

-85 Huang XF, Zavitsanou K, Huang X, Yu Y, Wang H, Chen F, Lawrence AJ, Deng C: Dopamine transporter and D2 receptor binding densities in mice prone or resistant to chronic high fat diet-induced obesity. Behav Brain Res 2006;175:415-419.

-86 Robinson TE, Berridge KC: The neural basis of drug craving: an incentive-sensitization theory of addiction. Brain Res Brain Res Rev 1993;18:247-291. 
87 Brown CM, Fletcher PJ, Coscina DV: Neuropeptide Y-induced operant responding for sucrose is not mediated by dopamine. Peptides 1998;19:1667-1673.

-88 Alsio J, Olszewski PK, Norback AH, Gunnarsson ZE, Levine AS, Pickering C, Schioth HB: Dopamine D1 receptor gene expression decreases in the nucleus accumbens upon long-term exposure to palatable food and differs depending on diet-induced obesity phenotype in rats. Neuroscience 2010;171:779-787.

89 Geiger BM, Haburcak M, Avena NM, Moyer MC, Hoebel BG, Pothos EN: Deficits of mesolimbic dopamine neurotransmission in rat dietary obesity. Neuroscience 2009;159:1193-1199.

$\$ 90$ Johnson PM, Kenny PJ: Dopamine D2 receptors in addiction-like reward dysfunction and compulsive eating in obese rats. Nat Neurosci 2010;13:635-641.

$\$ 91$ Sclafani A, Springer D: Dietary obesity in adult rats: similarities to hypothalamic and human obesity syndromes. Physiol Behav 1976;17:461-471.

-92 Rogers PJ: Returning 'cafeteria-fed' rats to a chow diet: negative contrast and effects of obesity on feeding behaviour. Physiol Behav 1985;35:493-499.

-93 Ranaldi R, Pocock D, Zereik R, Wise RA: Dopamine fluctuations in the nucleus accumbens during maintenance, extinction, and reinstatement of intravenous D-amphetamine self-administration. J Neurosci 1999; 19:4102-4109.

$\$ 94$ Vanderschuren LJ, Everitt BJ: Drug seeking becomes compulsive after prolonged cocaine self-administration. Science 2004;305:1017-1019.

$\$ 95$ Heyne A, Kiesselbach C, Sahun I, McDonald J, Gaiffi M, Dierssen M, Wolffgramm J: An animal model of compulsive food-taking behaviour. Addict Biol 2009;14:373-383.

-96 Lindblom J, Opmane B, Mutulis F, Mutule I, Petrovska R, Klusa V, Bergstrom L, Wikberg JE: The MC4 receptor mediates alpha-MSH induced release of nucleus accumbens dopamine. Neuroreport 2001;12:2155-2158.

-97 Narita M, Nagumo Y, Hashimoto S, Narita M, Khotib J, Miyatake M, Sakurai T, Yanagisawa M, Nakamachi T, Shioda S, Suzuki T: Direct involvement of orexinergic systems in the activation of the mesolimbic dopamine pathway and related behaviors induced by morphine. J Neurosci 2006;26:398-405.

-98 Trigo JM, Martin-Garcia E, Berrendero F, Robledo P, Maldonado R: The endogenous opioid system: a common substrate in drug addiction. Drug Alcohol Depend 2010;108:183-194.

$\$ 99$ Mansour A, Fox CA, Akil H, Watson SJ: Opioid-receptor mRNA expression in the rat CNS: anatomical and functional implications. Trends Neurosci 1995;18:22-29.

100 Hirose N, Murakawa K, Takada K, Oi Y, Suzuki T, Nagase H, Cools AR, Koshikawa N: Interactions among muand delta-opioid receptors, especially putative delta1- and delta2-opioid receptors, promote dopamine release in the nucleus accumbens. Neuroscience 2005;135:213-225.

101 Johnson SW, North RA: Opioids excite dopamine neurons by hyperpolarization of local interneurons. J Neurosci 1992;12:483-488.

102 Georges F, Stinus L, Bloch B, Le Moine C: Chronic morphine exposure and spontaneous withdrawal are associated with modifications of dopamine receptor and neuropeptide gene expression in the rat striatum. Eur J Neurosci 1999;11:481-490.

103 Marks-Kaufman R: Increased fat consumption induced by morphine administration in rats. Pharmacol Biochem Behav 1982;16:949-955.

104 Islam AK, Bodnar RJ: Selective opioid receptor antagonist effects upon intake of a high-fat diet in rats. Brain Res 1990;508:293-296.

105 Zhang M, Gosnell BA, Kelley AE: Intake of high-fat food is selectively enhanced by mu opioid receptor stimulation within the nucleus accumbens. J Pharmacol Exp Ther 1998;285:908-914.

106 Matthes HW, Maldonado R, Simonin F, Valverde O, Slowe S, Kitchen I, Befort K, Dierich A, Le Meur M, Dolle P, Tzavara E, Hanoune J, Roques BP, Kieffer BL: Loss of morphine-induced analgesia, reward effect and withdrawal symptoms in mice lacking the mu-opioid-receptor gene. Nature 1996;383:819-823.

107 Will MJ, Franzblau EB, Kelley AE: Nucleus accumbens mu-opioids regulate intake of a high-fat diet via activation of a distributed brain network. J Neurosci 2003;23:2882-2888.

108 Gosnell BA, Levine AS: Reward systems and food intake: role of opioids. Int J Obes (Lond) 2009;33(suppl 2):S54-58.

109 Apfelbaum M, Mandenoff A: Naltrexone suppresses hyperphagia induced in the rat by a highly palatable diet. Pharmacol Biochem Behav 1981;15:89-91.

110 Colantuoni C, Rada P, McCarthy J, Patten C, Avena NM, Chadeayne A, Hoebel BG: Evidence that intermittent, excessive sugar intake causes endogenous opioid dependence. Obes Res 2002;10:478-488.

111 Delamater AR, Sclafani A, Bodnar RJ: Pharmacology of sucrose-reinforced place-preference conditioning: effects of naltrexone. Pharmacol Biochem Behav 2000;65:697-704.

112 Jain R, Mukherjee K, Singh R: Influence of sweet tasting solutions on opioid withdrawal. Brain Res Bull 2004;64:319-322.

113 Zhang M, Kelley AE: Opiate agonists microinjected into the nucleus accumbens enhance sucrose drinking in rats. Psychopharmacology (Berl) 1997;132:350-360.

114 Gosnell BA, Majchrzak MJ: Centrally administered opioid peptides stimulate saccharin intake in nondeprived rats. Pharmacol Biochem Behav 1989;33:805-810.

$\$ 115$ Kirkham TC: Enhanced anorectic potency of naloxone in rats sham feeding 30\% sucrose: reversal by repeated naloxone administration. Physiol Behav 1990;47:419-426. 
116 Kelley AE, Bakshi VP, Haber SN, Steininger TL, Will MJ, Zhang M: Opioid modulation of taste hedonics within the ventral striatum. Physiol Behav 2002;76:365-377.

117 Leibel RL: Molecular physiology of weight regulation in mice and humans. Int J Obes (Lond) 2008;32(suppl 7):S98-108.

118 Hamdi A, Porter J, Prasad C: Decreased striatal D2 dopamine receptors in obese Zucker rats: changes during aging. Brain Res 1992;589:338-340.

119 Volkow ND, Wang GJ, Telang F, Fowler JS, Thanos PK, Logan J, Alexoff D, Ding YS, Wong C, Ma Y, Pradhan K: Low dopamine striatal D2 receptors are associated with prefrontal metabolism in obese subjects: possible contributing factors. Neuroimage 2008;42:1537-1543.

120 Tung YC, Yeo GS: From GWAS to biology: lessons from FTO. Ann N Y Acad Sci 2011;1220:162-171.

121 Levy CM, MacRae A, Koster EP: Perceived stimulus complexity and food preference development. Acta Psychol (Amst) 2006;123:394-413.

122 Mela DJ: Eating for pleasure or just wanting to eat? Reconsidering sensory hedonic responses as a driver of obesity. Appetite 2006;47:10-17.

123 Beckett ST: The Science of Chocolate; 2nd ed. Cambridge, RSC Publishing, 2008.

124 Michener W, Rozin P: Pharmacological versus sensory factors in the satiation of chocolate craving. Physiol Behav 1994;56:419-422.

125 Bruinsma K, Taren DL: Chocolate: food or drug? J Am Diet Assoc 1999;99:1249-1256.

126 Liang NC, Hajnal A, Norgren R: Sham feeding corn oil increases accumbens dopamine in the rat. Am J Physiol Regul Integr Comp Physiol 2006;291:R1236-1239.

127 Mattes RD: Oral fat exposure increases the first phase triacylglycerol concentration due to release of stored lipid in humans. J Nutr 2002;132:3656-3662.

128 Cummings DE, Weigle DS, Frayo RS, Breen PA, Ma MK, Dellinger EP, Purnell JQ: Plasma ghrelin levels after diet-induced weight loss or gastric bypass surgery. N Engl J Med 2002;346:1623-1630.

-129 Jerlhag E, Egecioglu E, Dickson SL, Andersson M, Svensson L, Engel JA: Ghrelin stimulates locomotor activity and accumbal dopamine-overflow via central cholinergic systems in mice: implications for its involvement in brain reward. Addict Biol 2006;11:45-54.

130 Overduin J, Figlewicz D, Cummings DE: Ghrelin affects motivational, but not hedonic aspects of feeding, NAASO Annual Scientific Meeting, New Orleans, LA, 2007.

131 Sørensen LB, Moller P, Flint A, Martens M, Raben A: Effect of sensory perception of foods on appetite and food intake: a review of studies on humans. Int J Obes Relat Metab Disord 2003;27:1152-1166.

132 Small DM, Gerber JC, Mak YE, Hummel T: Differential neural responses evoked by orthonasal versus retronasal odorant perception in humans. Neuron 2005;47:593-605.

133 Ruijschop RM, Boelrijk AE, de Ru JA, de Graaf C, Westerterp-Plantenga MS: Effects of retro-nasal aroma release on satiation. Br J Nutr 2008;99:1140-1148.

134 Drewnowski A, Schwartz M: Invisible fats: sensory assessment of sugar/fat mixtures. Appetite 1990;14: 203-217.

135 Drewnowski A: The real contribution of added sugars and fats to obesity. Epidemiol Rev 2007;29:160-171.

136 Rolls BJ., The role of energy density in the overconsumption of fat. J Nutr, 2000;130(2 suppl):268S-271S.

137 Andrade AM, Greene GW, Melanson KJ: Eating slowly led to decreases in energy intake within meals in healthy women. J Am Diet Assoc 2008;108:1186-1191.

-138 de Araujo IE, Oliveira-Maia AJ, Sotnikova TD, Gainetdinov RR, Caron MG, Nicolelis MA, Simon SA: Food reward in the absence of taste receptor signaling. Neuron 2008;57:930-941.

139 Overduin J, Frayo RS, Grill HJ, Kaplan JM, Cummings DE: Role of the duodenum and macronutrient type in ghrelin regulation. Endocrinology 2005;146:845-850.

140 Cummings DE, Overduin J: Gastrointestinal regulation of food intake. J Clin Invest 2007;117:13-23.

141 Rehfeld JF: A centenary of gastrointestinal endocrinology. Horm Metab Res 2004;36:735-741.

142 Woods SC: The control of food intake: behavioral versus molecular perspectives. Cell Metab 2009;9:489498.

143 Figlewicz DP, Benoit SC: Insulin, leptin, and food reward: update 2008. Am J Physiol Regul Integr Comp Physiol 2009;296:R9-19.

144 Veldhorst M, Smeets A, Soenen S, Hochstenbach-Waelen A, Hursel R, Diepvens K, Lejeune M, LuscombeMarsh N, Westerterp-Plantenga M: Protein-induced satiety: effects and mechanisms of different proteins. Physiol Behav 2008;94:300-307.

-145 Teff KL, Elliott SS, Tschop M, Kieffer TJ, Rader D, Heiman M, Townsend RR, Keim NL, D'Alessio D, Havel PJ: Dietary fructose reduces circulating insulin and leptin, attenuates postprandial suppression of ghrelin, and increases triglycerides in women. J Clin Endocrinol Metab 2004;89:2963-2972.

146 Hoad CL, Rayment P, Spiller RC, Marciani L, Alonso Bde C, Traynor C, Mela DJ, Peters HP, Gowland PA: In vivo imaging of intragastric gelation and its effect on satiety in humans. J Nutr 2004;134:2293-2300.

147 Boirie Y, Dangin M, Gachon P, Vasson MP, Maubois JL, Beaufrere B: Slow and fast dietary proteins differently modulate postprandial protein accretion. Proc Natl Acad Sci U S A 1997;94:14930-14935.

148 Ramirez I: Stimulation of fluid intake by maltodextrins and starch. Physiol Behav 1995;57:687-92.

149 Singh J, Dartois A, Kaur L: Starch digestibility in food matrix: a review. Trends Food Sci Technol 2010;21: 168-180. 
150 Gentilcore D, Chaikomin R, Jones KL, Russo A, Feinle-Bisset C, Wishart JM, Rayner CK, Horowitz M: Effects of fat on gastric emptying of and the glycemic, insulin, and incretin responses to a carbohydrate meal in type 2 diabetes. J Clin Endocrinol Metab 2006;91:2062-2067.

151 Larsen TM, Dalskov SM, van Baak M, Jebb SA, Papadaki A, Pfeiffer AF, Martinez JA, Handjieva-Darlenska T, Kunesova M, Pihlsgard M, Stender S, Holst C, Saris WH, Astrup A; Diet, Obesity, and Genes (Diogenes) Project: Diets with high or low protein content and glycemic index for weight-loss maintenance. N Engl J Med 2010;363:2102-2113.

152 Berthoud HR, Morrison C: The brain, appetite, and obesity. Annu Rev Psychol 2008;59:55-92.

153 Peyron C, Tighe DK, van den Pol AN, de Lecea L, Heller HC, Sutcliffe JG, Kilduff TS: Neurons containing hypocretin (orexin) project to multiple neuronal systems. J Neurosci 1998;18:9996-10015.

154 Morton GJ, Blevins JE, Kim F, Matsen M, Figlewicz DP: The action of leptin in the ventral tegmental area to decrease food intake is dependent on Jak-2 signaling. Am J Physiol Endocrinol Metab 2009;297:E202-210.

155 Belitz HD, Grosch W, Schieberle P: Food Chemistry, 4th ed. Heidelberg, Springer, 2009.

156 Colantuoni C, Rada P, McCarthy J, Patten C, Avena NM, Chadeayne A, Hoebel BG: Evidence that intermittent, excessive sugar intake causes endogenous opioid dependence. Obes Res 2002;10:478-488.

157 Pickering C, Alsio J, Hulting AL, Schioth HB: Withdrawal from free-choice high-fat high-sugar diet induces craving only in obesity-prone animals. Psychopharmacology (Berl) 2009;204:431-443.

158 Geiger BM, Behr GG, Frank LE, Caldera-Siu AD, Beinfeld MC, Kokkotou EG, Pothos EN: Evidence for defective mesolimbic dopamine exocytosis in obesity-prone rats. FASEB J 2008;22:2740-2746.

159 Lenoir M, Serre F, Cantin L, Ahmed SH: Intense sweetness surpasses cocaine reward. PLoS One 2007; 2:e698.

160 Lenard NR, Zheng H, Berthoud HR: Chronic suppression of mu-opioid receptor signaling in the nucleus accumbens attenuates development of diet-induced obesity in rats. Int J Obes (Lond) 2010;34:1001-1010. 